\title{
The usage of the term "formefruste" in ophthalmology
}

\section{Editorial}

In this editorial, I aimed to clarify the term "formefruste" and to take care to avoid its unnecessary use. Formefruste is a term defining", an incomplete or partial or arrested or in apparent or atypical or aborted or attenuated phenotypic expression or manifestation of a clinical entity or disease or syndrome or pathological condition. It often defines that disease is subclinical and that disease has not the main diagnostic criteria and the expected and common course of the disease. ${ }^{1}$ In ophthalmological terminology, the term "formefruste" has been used to call "the occult form of an ocular disease". To literature, the ophthalmological diseases in which the term has been used are keratoconus (KK), anterior segment dysgenesis, central serous chorioretinopathy, retinopathy of prematurity, hemorrhagic occlusive retinal vasculitis, juvenile idiopathic arthritis-associated uveitis, sympathetic uveitis, focal choroidal excavation in serpiginous choroiditis. ${ }^{2-11}$ Additionally, it has been also reported for defining of atypical clinical forms of some neuro-ophthalmological diseases such as multiple sclerosis, tuberosis sclerosis, Vogt-Koyanagi Syndrome and idiopathic intracranial hypertension, trilateral retinoblastoma and acnea rosacea as dermatological disease. ${ }^{12-17}$ Actually, any ocular finding may be a sign of a formefruste of any ocular, extraocular or systemical disease. Additionally, the term "formefruste" has been not been choiced in ophthalmological literature except only for the nomenclature of the frank, early stage or subclinical or preclinical or symptomless manifestation of KK for a long time. ${ }^{18,19}$ Formefruste KK has mild corneal topographic characteristics suggestive of an early subclinical KK., ${ }^{2,18,19}$ To my opinion, the usage of a term "occult" or "atypical" seems more appropriate for incomplete forms of the ocular diseases instead of the terms of "formefruste" and "subclinical disease".

\section{Conflicts of interest}

The author declares that there is no conflict of interest regarding the publication of this paper.

\section{Acknowledgments}

None.

\section{References}

1. Forme_fruste

2. Saad A, Gatinel D. Topographic and tomographic properties of forme fruste keratoconus corneas. Invest Ophthalmol Vis Sci. 2010;51(11):55465555.

3. Banitt MR, Romano A, Iragavarapu S, et al. Forme fruste anterior segment dysgenesis. Br J Ophthalmol. 2011;95(12):1756-1757.

4. Spaide RF. Central Serous Chorioretinopathy. In: Holz FG \& Spaide RF. Editors. Medical Retina. Essentials in Ophthalmology. Springer, Berlin, Heidelberg, Germany. 2005; p. 6-93.

5. Silverman WA. ROP_formefruste. J Perinatol. 2001;21(6):393-394.
Volume 7 Issue 5 - 2017

Burak Turgut
Department of Ophthalmology, Yukseklhtisas University, Faculty
of Medicine, Turkey

Correspondence: Burak Turgut, Department of Ophthalmology, Faculty of Medicine, Full Professor of Ophthalmology, Yukseklhtisas University, 06520, Ankara, Turkey, Tel+90312280360I, Email burakturgut@yiu.edu.tr

Received: October 12, 2017| Published: October 12, 2017

6. Baum JD. Retinal photography in premature infants: forme frusta retrolental fibroplasia. Proc R Soc Med. 1971;64(7):777-779.

7. Goldberg RA, Crawford C, Heier JS. Postoperative Hemorrhagic Occlusive Retinal Vasculitis: A Forme Fruste Variant? Retin Cases Brief Rep. 2016.

8. Dashti SR, Robinson S, Rodgers $\mathrm{M}$, et al. Pineal region giant cell astrocytoma associated with tuberous sclerosis: case report. J Neurosurg. 2005;102(3 Suppl):322-325.

9. Shields JA, Eagle RC, Shields CL, et al. Aggressive Retinal Astrocytomas in Four Patients with Tuberous Sclerosis Complex. Trans Am Ophthalmol Soc. 2004; 102:139-148.

10. Kotaniemi K, Savolainen A, Aho K. Severe childhood uveitis without overt arthritis. Clin Exp Rheumatol. 2003;21(3):395-398.

11. Roy R, Saurabh K, Vyas C, et al. Forme fruste focal choroidal excavation in a case of serpiginous choroiditis. Clin Exp Optom. 2017.

12. Burton EV, Greenberg BM, Frohman EM. Optic neuritis: A mechanistic view. Pathophysiology. 2011;18(1):81-92.

13. Yanoff M, Sassani JW. Granulomatous inflammation. In: Myron Yanoff \& Joseph W Sassani, editors. Ocular Pathology E-Book: Expert Consult. 7th ed. Elsevier-Saunders, London, 2015; 67 p.

14. O'Keefe GA, Rao NA. Vogt-Koyanagi-Harada disease. Surv Ophthalmol. 2017;62(1):1-25.

15. Bahall M, Reyes AJ, Ramcharan K, et al. Neuro-Ophthalmological Manifestations after Intramuscular Medroxyprogesterone: A FormeFruste of Idiopathic Intracranial Hypertension? Neurol Int. 2016;8(3):6132.

16. Whittle IR, McClellan K, Martin FJ, et al. Concurrent pineoblastoma and unilateral retinoblastoma: a formefruste of trilateral retinoblastoma? Neurosurgery. 1987;17(3):500-505.

17. Blaustein BH, Gurwood AS. Recurrent phlyctenular keratoconjunctivitis: a forme fruste manifestation of rosacea. Optometry 2001;72(3):179-184.

18. Amsler M. [The "formefruste" of keratoconus] (Article in German]). Wien Klin Wochenschr. 1961.73:842-843.

19. Sinjab MM. Classifications and patterns of keratoconus and keratectasia. In: Quick Guide to the Management of Keratoconus. Springer, Berlin, Heidelberg, Germany. 2012; p. 13-58. 